\title{
Feminist Forum
}

\author{
Janet Ellis \\ North Texas State University
}

\section{What Is It?}

A means of providing information regarding professional development of female behavior analysts in (at least) three fields: education, institutional/clinical practice, and business. Our focus will be on discussion of behaviors required for success in these (and any other) areas; problems encountered by female behaviorists in their work settings; solutions that writers and readers have implemented; questions that writers and readers would like to have answered by other writers and readers.

\section{Why Is It?}

The raison $\mathrm{d}^{\prime}$ être for such a forum is best explained by this assertion:

Males have retained ceremonial control over almost all natural and cultural resources, even those produced by the technological behavior of women. Women have, perhaps consequently or perhaps antecedently, gained access to the technological reinforcers by way of making personal reinforcers contingent on access. (Glenn, 1986, p. 7)

It is time for women who have earned access to our culture's technological reinforcers to obtain them with their technological behavior rather than being forced into the position many people, especially women, have found themselves: using personal reinforcers to gain access to cultural resources. This column is designed to provide women and men the opportunity to reflect on ways they have dealt with such cultural contingencies or share ideas they have for helping others deal with such contingencies.

\section{How Is It?}

$B A S A$ has provided an arena in which we can meet biannually. We are earnestly soliciting manuscripts from journal readers that will provoke, inform, challenge, and generally satisfy the interests of feminists (female and male) in behavior analysis. We have asked some women we know and some women everyone will know to contribute to this forum. We invite all our readers to respond with articles and/ or letters giving us their alternative or consensual views, offering ideas for research possibilities, offering guidelines gained from personal experience or passed on by wise others, and providing material that may be useful to others, especially women entering our field. We hope that women trying to establish themselves in our field and women as well as men who just might need such a verbal community as this to help remind them why they are doing what they're trying to do will find these useful.

Our first two pieces have been contributed by Beth Sulzer-Azaroff and Betty K. Armstrong.

\section{References}

Glenn, S. S. (1986). Metacontingencies in Walden Two. Behavior Analysis \& Social Action Journal, 5 and 6, 2-8. 